\title{
Exposure of Urology Residents to the Management of Urethral Strictures in Saudi Arabia: Should the Program for Postgraduates Be Customized?
}

This article was published in the following Dove Press journal: Research and Reports in Urology

\section{Raed Almannie \\ Abdullah Alturki \\ Abdullah AISufyani \\ Waleed Alkhamis iD \\ Saleh Binsaleh iD \\ Fahad Alyami \\ Urology Division, Department of Surgery, College of Medicine, King Saud \\ University, Riyadh, Saudi Arabia}

Correspondence: Raed Almannie

Urology Division, Department of Surgery,

College of Medicine, King Saud University,

Riyadh, Saudi Arabia

Tel +966545008004

Email Ralmannie@ksu.edu.sa
Purpose: This study aimed to assess the exposure and knowledge of urology residents in the management of urethral stricture (US) and to determine if they would be able to perform urethroplasty after graduation and whether urethroplasty should be included as a competency in the training program.

Patients and Methods: An online survey was sent to all residents enrolled in any urology training program in Saudi Arabia. Fifty-eight (approximately 50\%) of the 114 residents who were sent the survey provided responses.

Results: Most of the residents (45 residents, 77.6\%) who responded were exposed to fewer than ten cases of US during their last year of training. Fifty-six residents (96.6\%) attended five or fewer urethroplasty procedures in their last year of training. Twenty-three $(40 \%)$ residents did not attend any urethroplasty procedure in the last year. The most common procedures attended by the residents were minimally invasive treatments ( $89 \%$ cystoscopy with dilatation and 79\% direct visual internal urethrotomy (DVIU)). Most residents responded that they would manage newly diagnosed $1 \mathrm{~cm}$ US with either cystoscopy and dilatation or with DVIU 53 (91\%). For the first recurrence of US, 46 (79\%) residents responded that they would still prefer dilatation or DVIU. For the second, third, and chronic recurrences of US, $20(34.5 \%), 6(10.3 \%)$, and $5(8.6 \%)$ residents, respectively, responded that they would perform dilatation or DVIU. Residents had low expectations for the success rate of urethroplasty; only $32(55.2 \%)$ residents thought it had a high success rate.

Conclusion: Urethroplasty is a specialized urological procedure, one that residents have variable exposure to. Privilege to perform such a procedure after graduating should be modified to ensure the best outcome for patients.

Keywords: urethral stricture, urethroplasty, resident training, specialized training

\section{Introduction}

Urethral stricture (US) is characterized by the narrowing of the urethral lumen due to spongiofibrosis, causing symptoms of urinary obstruction. ${ }^{1}$ Etiology can include trauma, inflammation, as well as iatrogenic and idiopathic causes, and varies according to the geographic location. A study found that the main etiology for US in India was external trauma, while iatrogenic causes were predominant in Italy and the USA. ${ }^{2}$ In the USA, it contributes to around 5000 inpatient admissions and over 1.5 million outpatient visits yearly. ${ }^{3}$ In the UK, 12,000 surgeries are performed annually to treat US. ${ }^{4}$

According to the guidelines of the American Urology Association (AUA) and the Société Internationale d'Urologie (SIU), short bulbar US without obliteration should be 
initially treated with minimally invasive procedures such as direct visual internal urethrotomy (DVIU) or cystoscopy with dilation; in cases of failure, urethroplasty can be considered. Some variations exist between the two guidelines whether urethroplasty should be considered after one failed minimally invasive treatment or after a second treatment. ${ }^{5,6}$

Urologists commonly perform minimally invasive procedures, due to the simplicity of the procedure and faster recovery of patients. Moreover, it does not require additional training. $^{7-9}$ However, it has a high rate of recurrence, ${ }^{10-13}$ and this pattern of practice might affect the knowledge and exposure of trainees in urology programs.

After graduating from a surgical training program, graduates are allowed to perform most, if not all, surgical procedures in their specialties. Some surgeries like reconstructive surgeries for US are specialized and considered complex. $^{14,15}$ Performing these surgeries without much prior experience or knowledge might affect the outcomes and may risk patient safety.

Our aim was to assess the exposure and knowledge of urology residents in the management of US, to determine if they would be able to perform urethroplasty after graduation and whether urethroplasty should be included as a competency in the training program.

\section{Materials and Methods}

This observational study was conducted in June 2017. An online survey was sent through email with an attached link to the survey created through Google forms to all residents enrolled in any urology training program in Saudi Arabia. Emails of all urology residents in the kingdom of Saudi Arabia were accorded from the Saudi Commission for Health Specialties which is the governing body for residency training. Duplication results were avoided by mandating each resident that fills out the form to enter in their unique residency training number. The survey was open from March 2017 till August 2017. Firstyear trainees were excluded from the study as they are required to undergo general surgery rotations in the first year.

The survey consisted of two parts. The first part included: location of the program, level of training, and the hospital. The second part consisted of ten questions to assess knowledge about and exposure to the management of US and included: number of urethroplasty surgeries attended, most commonly performed procedure, their approach in different US scenarios, their perception regarding the complexity and success of different urethroplasty procedures (Appendix 1).
Institutional Review Board (IRB) approval was acquired at King Saud University College of Medicine and King Khalid University Hospital, Riyadh, Saudi Arabia. Electronic informed consent was obtained from participants. Data were analyzed with descriptive analysis using IBM SPSS (Statistics for Windows, version 26; IBM Corp., Armonk, NY, USA).

\section{Results}

Fifty-eight (approximately 50\%) of 114 residents responded to the questions, and their demographic data are shown in Table 1. Most of the residents (45 residents, 77.6\%) were exposed to fewer than ten cases of US (Figure 1), while 56 (96.6\%) attended five or fewer urethroplasty procedures (Figure 2). Twenty three (40\%) residents did not attend any urethroplasty procedure in their last year of training.

The most common procedures attended by the residents were minimally invasive procedures (89\% cystoscopy with dilatation and $79 \%$ DVIU). For the different types of urethroplasties, the most common urethroplasty procedure attended was excision and primary anastomosis $(20 \%)$, while exposure to other types of urethroplasty was minimal (Table 2).

Most residents responded that they would manage newly diagnosed $1 \mathrm{~cm}$ US with either cystoscopy and dilatation or with DVIU 53 (91\%). For the first recurrence, $46(79 \%)$ residents responded that they would still prefer dilatation or DVIU. For the second, third, and chronic recurrence, $20(34.5 \%), 6(10.3 \%)$, and $5(8.6 \%)$ residents, respectively, responded that they would still perform

Table I Demographic Distribution

\begin{tabular}{|c|c|}
\hline \multicolumn{2}{|l|}{ Number of Respondents (\%) } \\
\hline Region of training in Saudi Arabia & $n=58(100 \%)$ \\
\hline Central & $26(44.8)$ \\
\hline Eastern & $12(20.7)$ \\
\hline Southern & $8(13.8)$ \\
\hline Western & $12(20.7)$ \\
\hline Hospital & $n=58(100 \%)$ \\
\hline Ministry of Health & $30(51.7)$ \\
\hline University & $9(15.5)$ \\
\hline Military & $19(32.8)$ \\
\hline Level of training & $n=58(100 \%)$ \\
\hline R2 & $14(24.1)$ \\
\hline R3 & $18(3 \mid)$ \\
\hline R4 & $15(25.9)$ \\
\hline R5 & $11(19)$ \\
\hline
\end{tabular}




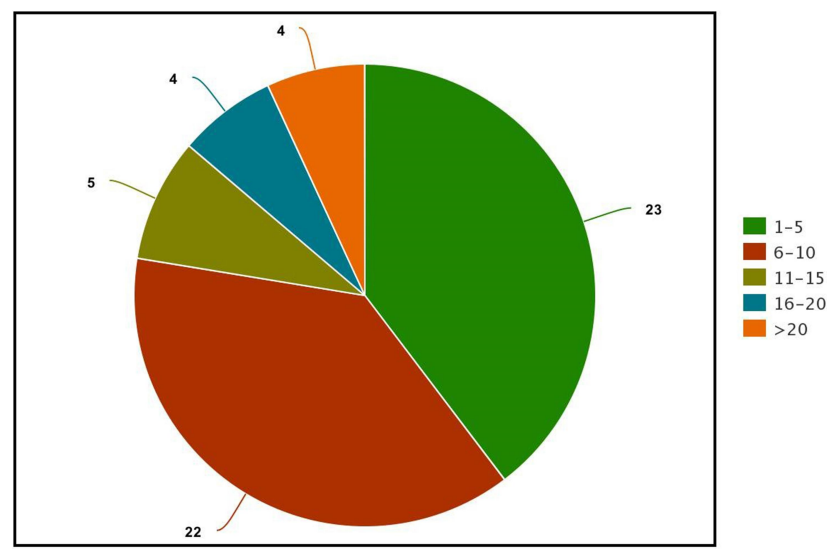

Figure I Number of urethral stricture cases managed last year.

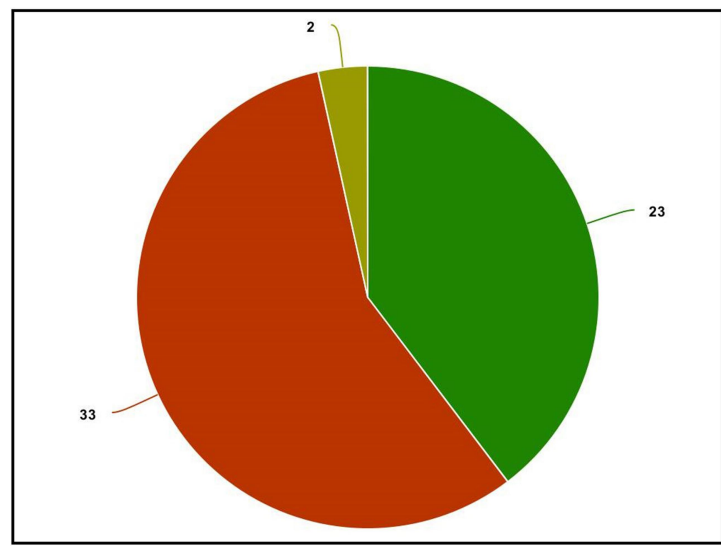

Figure 2 Number of urethroplasty procedures attended last year.

dilatation or DVIU. For the management of newly diagnosed stricture, none of the residents chose urethroplasty. For each subsequent recurrence, 7 (12.1\%), 30 (51.7\%), 48 $(82.8 \%)$, and $45(77.6 \%)$ residents responded that they would perform urethroplasty for the first, second, third, and chronic recurrences, respectively (Table 3 ).

Most residents perceived urethroplasty as a highly complex procedure. Fifty (83\%) residents and only 32 $(55.2 \%)$ residents were aware that urethroplasty has a high success rate (Table 4).

\section{Discussion}

Urethroplasty to treat US is considered a specialized surgery with a high learning curve. One study showed that experience of 100 urethroplasty procedures is required to achieve a good success rate. ${ }^{14}$ Another study showed that at the end of a 3-year fellowship, trainees were still limited in their skills to perform urethroplasty as independent practitioners. ${ }^{16}$ However, there are some centers with high
Table 2 Procedures Performed*

\begin{tabular}{|l|l|}
\hline Number of Respondents (\%) & \\
\hline Procedure & $52(89.7)$ \\
Cystoscopy and dilatation & $12(20.7)$ \\
Bougie à ouleboule blind dilatation & $46(79.3)$ \\
Visual urethrotomy & $7(12.1)$ \\
Laser urethrotomy & $13(22.4)$ \\
Stent placement urology Memokath & $12(20.7)$ \\
Excision and primary anastomosis & $4(6.9)$ \\
Ventral buccal graft urethroplasty & $8(13.8)$ \\
Dorsal buccal graft urethroplasty & $3(5.2)$ \\
Lateral buccal graft urethroplasty & $3(5.2)$ \\
Staged urethroplasty & $4(6.9)$ \\
Flap urethroplasty & $0(0)$ \\
Skin graft urethroplasty & $5(8.6)$ \\
Perineal urethrostomy &
\end{tabular}

Notes: *Total number of counts is more than total number of respondents, and total percentage is more than $100 \%$ because multiple answers were permitted.

cases of reconstructive surgeries where residents perform 50 urethroplasty surgeries annually as the primary surgeons. ${ }^{17}$

We found that residents' exposure to US cases was low; $45(77.6 \%)$ residents saw fewer than ten cases during their last year of training. Of those, more than half $(23$ residents, 40\%) saw five or fewer cases. This finding shows that there is a variation in exposure between residents. In addition, it proves that the exposure is not adequate compared to that reported in other studies. ${ }^{18}$

The residents' exposure to urethroplasty was poor; 56 (96.6\%) residents attended five or fewer cases during their last year of training. Of these, 23 (40\%) did not attend any procedure during their last year of training. Other international studies reported that the residents' exposure to urethroplasty was between 13 and 19 annually. ${ }^{18}$ A study in the same geographical area showed that only $11(4 \%)$ of 216 board-certified urologists performed 11 or more urethroplasties in one year and $63 \%$ of practicing urologists have never performed a urethroplasty. ${ }^{8}$ This further indicates a limited exposure of residents to urethroplasty.

There are some differences between the AUA and SIU guidelines in the management of US for the first recurrence after minimally invasive treatment. However, both guidelines recommend urethroplasty for the second recurrence of the disease. ${ }^{5,6}$ However, 20 (35\%) of our residents responded that they would still perform minimally invasive methods for the second recurrence. Furthermore, some residents responded that they would offer treatments that are not considered the standard of care and those included: 3 residents stated (5.2\%) urethral calibration, 4 
Table 3 Management of Urethral Strictures

\begin{tabular}{|l|l|}
\hline \multicolumn{2}{|l|}{ Number of Respondents (\%) } \\
\hline Newly diagnosed I-cm stricture \\
Urethral calibration (bougie à boule) & $4(6.9)$ \\
Internal urethrotomy or dilatation & $53(91.4)$ \\
Urethral stent & $0(0)$ \\
Clean intermittent catheterization & $1(1.7)$ \\
Urethroplasty & $0(0)$ \\
\hline First recurrence I-cm stricture & \\
Urethral calibration (bougie à boule) & $2(3.4)$ \\
Internal urethrotomy or dilatation & $46(79.3)$ \\
Urethral stent & $0(0)$ \\
Clean intermittent catheterization & $3(5.2)$ \\
Urethroplasty & $7(12.1)$ \\
\hline Second recurrence I-cm stricture & \\
Urethral calibration (bougie à boule) & $3(5.2)$ \\
Internal urethrotomy or dilatation & $20(34.5)$ \\
Urethral stent & $1(1.7)$ \\
Clean intermittent catheterization & $4(6.9)$ \\
Urethroplasty & $30(5 I .7)$ \\
\hline Third recurrence I-cm stricture & \\
Urethral calibration (bougie à boule) & $1(1.7)$ \\
Internal urethrotomy or dilatation & $6(10.3)$ \\
Urethral stent & $2(3.4)$ \\
Clean intermittent catheterization & $I(I .7)$ \\
Urethroplasty & $48(82.8)$ \\
\hline Chronic recurrence I-cm stricture & $45(77.6)$ \\
Urethral calibration (bougie à boule) & $2(3.4)$ \\
Internal urethrotomy or dilatation & $5(8.6)$ \\
Urethral stent & $2(3.4)$ \\
Clean intermittent catheterization & $4(6.9)$ \\
Urethroplasty & 45 \\
\hline
\end{tabular}

Table 4 Perception of Urethroplasty*

\begin{tabular}{|l|l|}
\hline \multicolumn{2}{|l|}{ Number of Respondents (\%) } \\
\hline Opinion Regarding Urethroplasty & $32(55.2)$ \\
High success rate & $50(86.2)$ \\
Complex procedure & $9(15.5)$ \\
Many complications & $9(15.5)$ \\
Low success rate & $1(1.7)$ \\
Easy procedure &
\end{tabular}

Notes: *Total number of counts is more than total number of respondents, and total percentage is more than $100 \%$ because multiple answers were permitted.

(7\%) residents stated clean intermittent catheterization, and $1(1.7 \%)$ resident stated urethral stents. A study showed similar results among local practicing urologists, where $85(39 \%)$ residents responded that they would recommend minimally invasive methods for a second recurrence. $^{8}$ A study in the USA showed that the boardcertified urologists' responses for management of a second recurrence were: 31 (7.2\%) stated endoscopic treatment, $47(11 \%)$ stated clean intermittent catheterization, and 59 (13.6\%) stated urethral stent. ${ }^{7}$

Most residents $(50,86 \%)$ perceived urethroplasty as a complex procedure while only 32 (55\%) residents believed it is a highly successful procedure. However, the success rate of the procedure is high and can reach $98.6 \%$ for anastomotic urethroplasty, and $89.9 \%$ for substitution urethroplasty with grafts. ${ }^{19}$

The current Saudi Council for Health Specialties (SCFHS) urology curriculum categorizes urethroplasty as a major open surgery for which residents must perform a minimum of two procedures during their four years of training. ${ }^{20}$ Based on our results and previous studies, ${ }^{8}$ we believe that attendance of urethroplasty procedures should not be a prerequisite to completion of a urology training program. The Royal College of Physicians and Surgeons of Canada urology training guidelines classifies urethroplasty as a Category $\mathrm{C}$ procedure, which means

The fully trained resident will be able to describe the following procedures, the indications for these procedures, and the perioperative complications that might be encountered. ${ }^{21}$

However, they are not required to participate in any of these procedures. A similar or modified classification can be followed in the SCFHS which would be more practical.

Our results revealed poor exposure of the urology residents to urethroplasty, which would affect their competency in performing this procedure. There were similar observations by other studies, wherein graduating residents were found to lack proficiency in reconstructive US surgery. ${ }^{22,23}$ While this will not affect the competency to become a well-trained general urologist, the limited exposure might compromise patient outcomes. This could be resolved by tailoring privileges for newly graduated urologists by only allowing them to perform specialized reconstructive surgery independently if a certain number of procedures is achieved in their surgical logbook.

Although this study investigated the exposure of residents to one specialized surgery, similar studies can be conducted for other procedures, including those not in the realm of urology. Understanding the residents' perception and exposure is a key element to customize programs to meet the needs of surgical trainees. ${ }^{23}$

Suboptimal response rate and lack of statistical analysis are considered limitations of this study. Furthermore, 
the questionnaire was not validated, nor did it include questions on the knowledge of urethroplasty. Future studies could be conducted to investigate a correlation between numbers of cases attended and knowledge of procedural steps for urethroplasty.

\section{Conclusion}

Urethroplasty is a specialized urological procedure, one that residents have variable exposure to. Privilege to perform such procedure after graduating should be modified to ensure the best outcome for patients.

\section{Acknowledgments}

We thank our colleagues from Research Center, Deanship of Scientific Research, College of Medicine, King Saud University, who provided insight and expertise that greatly assisted this research.

\section{Author Contributions}

All authors made a significant contribution to the work reported, whether that is in the conception, study design, execution, acquisition of data, analysis and interpretation, or in all these areas; took part in drafting, revising or critically reviewing the article; gave final approval of the version to be published; have agreed on the journal to which the article has been submitted; and agree to be accountable for all aspects of the work.

\section{Disclosure}

The authors report no conflicts of interest for this work.

\section{References}

1. Tritschler S, Roosen A, Füllhase C, Stief CG, Rübben H. Urethral stricture: etiology, investigation and treatments. Dtsch Arztebl Int. 2013;110(13):220-22226.

2. Stein DM, Thum DJ, Barbagli G, et al. A geographic analysis of male urethral stricture aetiology and location. BJU Int. 2013;112(6):830 834. doi:10.1111/j.1464-410X.2012.11600.x

3. Santucci RA, Joyce GF, Wise M. Male urethral stricture disease. J Urol. 2007;177(5):1667-1674. doi:10.1016/j.juro.2007.01.041

4. Mundy AR, Andrich DE. Urethral strictures. BJU Int. 2011;107 (1):6-26. doi:10.1111/j.1464-410X.2010.09800.x

5. Wessells H, Angermeier KW, Elliott S, et al. Male urethral stricture: American urological association guideline. J Urol. 2017;197(1):182190. doi:10.1016/j.juro.2016.07.087

6. Buckley JC, Heyns C, Gilling P, Carney J. SIU/ICUD consultation on urethral strictures: dilation, internal urethrotomy, and stenting of male anterior urethral strictures. Urology. 2014;83(3 Suppl):S18-S22. doi:10.1016/j.urology.2013.08.075
7. Bullock TL, Brandes SB. Adult anterior urethral strictures: a national practice patterns survey of board certified urologists in the United States. J Urol. 2007;177(2):685-690. doi:10.1016/j.juro.2006.09.052

8. Almannie RM, Alkhamis WH, Alshabibi AI. Management of urethral strictures: a nationwide survey of urologists in the Kingdom of Saudi Arabia. Urol Ann. 2018;10(4):363-368. doi:10.4103/UA.UA_58_18

9. van Leeuwen MA, Brandenburg JJ, Kok ET, Vijverberg PL, Bosch JL. Management of adult anterior urethral stricture disease: nationwide survey among urologists in the Netherlands. Eur Urol. 2011;60(1):159-166. doi:10.1016/j.eururo.2011.03.016

10. Khan S, Khan RA, Ullah A, et al. Role of clean intermittent self catheterisation (CISC) in the prevention of recurrent urethral strictures after internal optical urethrotomy. J Ayub Med Coll Abbottabad. 2011;23(2):22-25.

11. Hudak SJ, Atkinson TH, Morey AF. Repeat transurethral manipulation of bulbar urethral strictures is associated with increased stricture complexity and prolonged disease duration. J Urol. 2012;187 (5):1691-1695. doi:10.1016/j.juro.2011.12.074

12. Heyns CF, Steenkamp JW, De Kock ML, Whitaker P. Treatment of male urethral strictures: is repeated dilation or internal urethrotomy useful? J Urol. 1998;160(2):356-8. doi:10.1016/S0022-5347(01) 62894-5

13. Naudé AM, Heyns CF. What is the place of internal urethrotomy in the treatment of urethral stricture disease? Nat Clin Pract Urol. 2005;2(11):538-545. doi:10.1038/ncpuro0320

14. Faris SF, Myers JB, Voelzke BB, et al. Assessment of the male urethral reconstruction learning curve. Urology. 2016;89:137-142. doi:10.1016/j.urology.2015.11.038

15. Gill JD, Stewart LF, George NJ, Eardley I. Operative experience of urological trainees in the UK. BJU Int. 2012;109(9):1296-1301. doi:10.1111/j.1464-410X.2011.10579.x

16. Andrich DE, Mundy AR. A fellowship programme in reconstructive urological surgery: what is it and what is it for? BJU Int. 2010;106 (1):108-111.

17. Santucci RA. The reconstructive urology work force: present and future. Transl Androl Urol. 2014;3(2):205-208.

18. Silvestre J, Vincenza C, Hernandez J, Lee D. Longitudinal assessment of adult cases performed by graduating urology residents in the United States: 2010-2018. Urol Pract. 2020;7(1):53-60. doi:10.10 97/UPJ.0000000000000075

19. Robine E, Rigaud J, Luyckx F, et al. Analyse des taux de succès des urétroplasties pour sténoses de l'urètre bulbaire chez l'homme adulte: revue systématique de la littérature [Analysis of success rates of uretroplasty for adult male bulbar urethral stricture: a systematic review]. Prog Urol. 2017;27(2):49-57. doi:10.1016/j.purol.2016. 12.003

20. Available from: https://www.scfhs.org.sa/MESPS/TrainingProgs/ TrainingProgsStatement/Documents/Urology\%20new.pdf. Accessed August 22, 2020.

21. Royal college of physicians and surgeons of Canada objectives of training in urology; 2009. Available from: http://www.royalcollege. ca/cs/groups/public/documents/document/y2vk/mdaw/ edisp/ tztest3rcpsced000939.pdf.

22. Okhunov Z, Safiullah S, Patel R, et al. Evaluation of urology residency training and perceived resident abilities in the United States. J Surg Educ. 2019;76(4):936-948. doi:10.1016/j.jsurg.2019.02.002

23. Bachir BG, Aprikian AG, Kassouf W. Are Canadian urology residency programs fulfilling the Royal College expectations? A survey of graduated chief residents. Can Urol Assoc J. 2014;8(3-4):109-115. doi:10.5489/cuaj.1339 


\section{Publish your work in this journal}

Research and Reports in Urology is an international, peer-reviewed, open access journal publishing original research, reports, editorials, reviews and commentaries on all aspects of adult and pediatric urology in the clinic and laboratory including the following topics: Pathology, pathophysiology of urological disease; Investigation and treatment of urological disease; Pharmacology of drugs used for the treatment of urological disease. The manuscript management system is completely online and includes a very quick and fair peer-review system, which is all easy to use. Visit http://www.dovepress.com/ testimonials.php to read real quotes from published authors.

Submit your manuscript here: https://www.dovepress.com/research-and-reports-in-urology-journal 